\title{
Methodical foundations of cargo owners' transport services logistics management
}

\author{
Petro Yanovsky ${ }^{1}$, Viktoriia Yanovska ${ }^{2}$, Sergiy Lytvynenko ${ }^{3 *}$, Larysa Lytvynenko ${ }^{4}$, and Oleksandr Vodchic $^{11}$ \\ ${ }^{1}$ National Aviation University, Military Training Department, 03058 Kyiv, Ukraine \\ ${ }^{2}$ State University of Infrastructure and Technology, Department of Economics, Marketing and Business Administration 04073 Kyiv, \\ Ukraine \\ ${ }^{3}$ National Aviation University, International Economy Department, 03058 Kyiv, Ukraine \\ ${ }^{4}$ National Aviation University, Management of Foreign Economic Activity of Enterprises Department, 03058 Kyiv, Ukraine
}

\begin{abstract}
In the article methodical foundations of transport services logistics management of cargo owners were realized, on the basis of integrated estimation of economic efficiency of holistic progressive logistic chain operation of cargo delivery. In the making of the study, the authors have identified the provision of logistic management conditions by production and mainline rail transport in carrying out transportations. In the successful implementation of finished product loading and arriving cargo processing plans, clear interaction of all logistics chain elements is an important factor, achieved on the basis of introduction of a stable cargo train schedule at sections and the submission of local operation organization in nodes, at sections and stations. On the basis of modelling possible variants of different parameters ratios of the logistic interaction process of production with mainline rail transport, it was determined that at different parameters ratios results can be obtained that will vary by waiting time of carrying out loading in railway cars and waiting time of removal of finished products from manufacturer's warehouse, required car fleet and loading of material handling vehicles. In this case, the most economical option should be taken as the main condition for ensuring a rational interaction of industrial and mainline rail transport.
\end{abstract}

\section{Introduction}

Driven by the need to initiate the restoration of the state's economy and the need to bring up rapidly its functioning to the level desirable by the society, priority is given to solving problems on the improvement of relations between cargo owners and railways on mutually beneficial conditions, technical and technological re-equipment of mainline and industrial rail transport. The issue of searching for a complex of effective measures the implementation of which in the operation of railways will improve the use of limited resources and increase the quality of transport services, in current conditions of economic, financial and monetary relations' globalization among the states is of particular relevance.

The uneven distribution of producers and consumers of specific products in the state territory, and also the corresponding natural resources, leads to uneven concentration of works related to loading and unloading of cars on Ukrainian railways. Quite frequently, railway cars of one type arrive for unloading at the station, and for loading there is a need for railway cars of another type. The unevenness of territorial division of works on loading and unloading increase by seasonality of carrying specific cargoes, requiring the transfer a certain number of appropriate rolling stock to performance points in the short term. Notwithstanding such unevenness, any railway should have specific quantity of cargo resources of railway cars on a daily basis in order to provide stable and rhythmic production operation. Due to this full amount of scheduled and additional loading and departures for the purpose of finished products should be provided.

Transport production is the foundation of a market economy. Therefore, it acts as a subject of market relations, the quality of operation of which affects the effective functioning and development of all industries of national economy served by transport. The provision of rational interaction of railways, industrial structures and consumer organizations in establishing mutually beneficial economic-legal relations between transport and cargo owners is particularly important in economic development, i.e. through the implementation of a compromise management of the transport process on the equal participation of all its participants.

\section{Literature review and defining the problem}

Many Ukrainian and foreign scholars were engaged in studying the issues of logistics management in railway transport. The most significant contribution to solving scientific problems on this issue was made by $\mathrm{E}$. Alyoshinsky, G. Bogomazova, T. Butko, H. Kyrychenko, O. Lavrukhin, D. Lomotko, S. Panchenko,

Corresponding author: sllitvinenko1982@gmail.com 
L. Parkhomenko, A. Prokhorchenko, O. Shander, O. Shapatina, G. Zambrybor, V. Zapara, Y. Zapara, and Y. Yue. Research papers of B. Abramovic, E. Nedeliakova, M. Panak, D. Sipus, J. Sabino, J. Leal, T. Stützle, M. Birattari, L. Kuttner are of particular interest.

The papers [1-6] suggest approaches to solve the problem of train routing. D.R. Martinelli and H. Teng in [1] explore neural networks for obtaining good solutions in short time periods for the train formation problem. G. de O. Ramos and A.L.C. Bazzan in [2] present the use of the GRASP metaheuristic, propose a novel performance evaluation function, which measures the number of vehicles having an incentive to deviate from the routes to which they were assigned. A novel performance metric was introduced, which measures the amount of vehicles assigned to non-least cost routes. This approach outperforms the well-known method of successive averages providing considerably fairer assignments. In paper [6] a genetic algorithm to compute an approximate solution that seeks to minimize the average travel time was applied, a non-trivial network was used departing from binary route choice scenarios.

L. Kuttner in [7] proposed an option to optimize designing networks in the cargo service of German railways, which is an interesting and original modern approach to solving the issue. Scholars J. Sabino, J. Leal, T. Stützle and M. Birattari in [8] offered an algorithm for optimizing the operational planning of the railway station performance. The proposed algorithm minimizes the multi-purpose function, which considers both fixed and variable transport costs associated with the movement of railway cars in the area of the railway station's yard. An attempt to monitor the synergy of logistic processes in railway transport was carried out by B. Abramovic, E. Nedeliakova, M. Panak and D. Sipus in [9]. The results of the study allowed estimating costs for quality logistics processes in railway transport.

\section{Research aim and objectives}

The aim of the research is to develop the methodical bases of cargo owners' transport service logistics management.

To achieve the purpose, the following tasks were identified:

- to carry out a comprehensive assessment of the economic efficiency of the functioning a holistic progressive logistic chain of cargo delivery (LCCD);

- to identify possible variants of different parameters ratios of the logistic interaction process of production with mainline rail transport;

- to evaluate the results of modelling the interaction between the finished products' accumulation process in the manufacturer's warehouse and the system of supplying empty car in the logistics chain "Production Mainline Rail Transport".

\section{Overview key findings}

\subsection{Providing the condition of production and mainline rail transport logistic management in performing carriage}

Improvement of cargo owners' transport service should be carried out with a view to ensure competitiveness and profitability of railways at the stage of their reformation and integration into the EU. Due to limited resources, successful accomplishment of this complex task is provided by the implementation of logistic principles at all stages of the transport process, taking into account the interests of clients, intermediaries, operators and the carrier. As D. Lomotko in [10] and T. Yanovska in [11] rightly pointed out, in the context of economic market transformations the requirements of the clientele to the quality of transport services are increased while increasing competition from the side of railways. As indicated by the results of the researches carried out, a comprehensive solution to all problems with the cargo transportation can be achieved by designing logistic chains of cargo delivery (LCCD), minimizing the function of total costs of the operation of the logistics chain "Production - Mainline Rail Transport" (LCPMRT) presented by equation (1), which takes into account all costs of the carrier when sending a batch of finished products (Fig. 1).

$$
\begin{aligned}
& \sum E_{t o t}=365 \cdot Q_{d} \cdot \frac{q_{l}^{a}}{q_{l}^{p}} \cdot\left[t_{d e l}^{s t}\left(C_{d e l}+P_{c}+C_{s t r}^{s t}+C_{p a y}^{t c}\right)+\right. \\
& \left.+t_{d e l}^{d} \cdot\left(\frac{C_{d e l}^{d}}{L_{s}}+C_{d e l}^{w}\right)\right] \geq C_{l u v} \cdot E_{n}+C_{m n}
\end{aligned}
$$

where $Q_{d}$ - daily cargo traffic, t; $q_{l}^{a}$ - actual hourly productivity of loading and unloading vehicle, $\mathrm{t} / \mathrm{h} ; q_{l}^{p}-$ planned hourly productivity of loading and unloading vehicle, $\mathrm{t} / \mathrm{h} ; t_{d e l}^{s t}$ - delay of 1 tonne of cargo per day at the station; $C_{d e l}-$ costs of delay 1 ton of cargo for 1 hour, UAH; $P_{c}$ - price per 1 ton of cargo; $C_{s t r}^{s t}-$ amount of payment for the storage of 1 ton of cargo for 1 hour at the station by the cargo owner, UAH; $C_{p a y}^{t c}-$ amount of payment for the use of station tracks and cars by the cargo owner to the railway, $\mathrm{UAH} ; t_{d e l}^{d}-$ duration of delay 1 ton of cargo on the driveway per day, h; $C_{d e l}^{d}-$ the cost of delay for 1 hour 1 tonne of cargo on the driveway; $L_{s}-$ static load of the railway car, $\mathrm{t} / \mathrm{car} ; C_{d e l}^{w}$ - costs for delays of 1 ton of finished products at manufacturer's warehouse for 1 hour, UAH; $C_{l u v}-$ cost of used loading and unloading vehicles and other technical means; $E_{n}-$ normative coefficient of investment efficiency; $C_{m n}-$ costs for maintenance of introduced modern loading and unloading vehicles and other technical means, UAH.

Result (1) considers the operation of the logistics chain "Production - Mainline Rail Transport" without taking into account its interaction with other parts of the entire transport and logistic system (TLS). Therefore, it 
must be evaluated as the previous one. To obtain the final result, it is necessary to carry out a comprehensive assessment of economic efficiency of the functioning of a progressive logistic chain of cargo delivery.

High-quality interaction of industrial and mainline transport involves the organization of the work of all basic elements of the logistics chain in a single technology providing rhythmic reception and dispatch of trains, coordinated shunting movements, even distribution of loading and unloading for 24 hours and by days of the week.

\begin{tabular}{|c|c|}
\hline Delay of loaded railway cars at the adjoining station & Delay of railway cars in the driveway \\
\hline$\downarrow$ & $\downarrow$ \\
\hline $\begin{array}{l}\text { Technological implications: } \\
\text { - occupation of station tracks (deterioration of the station } \\
\text { manoeuvring capability); } \\
\text { - increase in downtimes at the station (slowing down car turnover). }\end{array}$ & \begin{tabular}{|l} 
Technological implications: \\
- an increase in car residence time at the enterprise.
\end{tabular} \\
\hline$\downarrow$ & 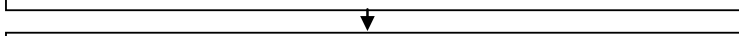 \\
\hline $\begin{array}{l}\text { Economic impacts: } \\
\text { - financial losses of the enterprise due to untimely receipt of } \\
\text { cargoes resulted in a violation of the production process }-\mathrm{E}_{1} \text {; } \\
\text { - costs due to the cargo mass slowdown }-\mathrm{E}_{2} \text {; } \\
\text { - payment for cargo storage and use of railway stations and cars }-\mathrm{E}_{3} \text {. }\end{array}$ & $\begin{array}{l}\text { Economic impacts: } \\
\text { - payment for the use of cars to the the railway }-\mathrm{E}_{4} \text {; } \\
\text { - costs for delays of finished products in the manufacturer's } \\
\text { warehouse }-\mathrm{E}_{5} \text {. }\end{array}$ \\
\hline \multicolumn{2}{|c|}{$\begin{array}{l}\text { Reason: insufficient processing of cargo front capacities due to outdated and worn-out loading and unloading vehicles and their } \\
\text { lack of productivity during periods of congestion of cargo operations, insufficient length of fronts. }\end{array}$} \\
\hline \multicolumn{2}{|l|}{$\downarrow$} \\
\hline Activities to address: replacement of existing fleet of & $\mathrm{h}$ modern ones, \\
\hline
\end{tabular}

Fig. 1. Providing the condition of production and mainline rail transport logistic management in performing carriage

Herewith, the clear interaction of all elements of the logistics chain is an important factor in the successful implementation of the plans for loading finished products and processing of arriving cargo.

As evidenced by the best practices of railways and the results of scientific researches, such a clear interaction and harmonization can be achieved on the basis of the introduction of a stable schedule of cargo trains at sections and subordination of the local operation organization to it in nodes, at sections and stations.

To implement it in the practical conditions of servicing each cargo front, the supply-arrival of car groups should be subordinated to such a schedule. Given the rather high stability of production processes at large enterprises, the moments of departure of car groups with finished products should be established at the same time intervals, equal to the interval of accumulation of the shipment at manufacturer's warehouse $\overline{I_{a c}}$. Planned moments of the end of the accumulation of the shipment $q$ need to be clearly aligned with the corresponding paths of a stable schedule of cargo trains at stations.

The scheme of accumulating the shipment of products at the manufacturer's station is shown in Fig. 2.

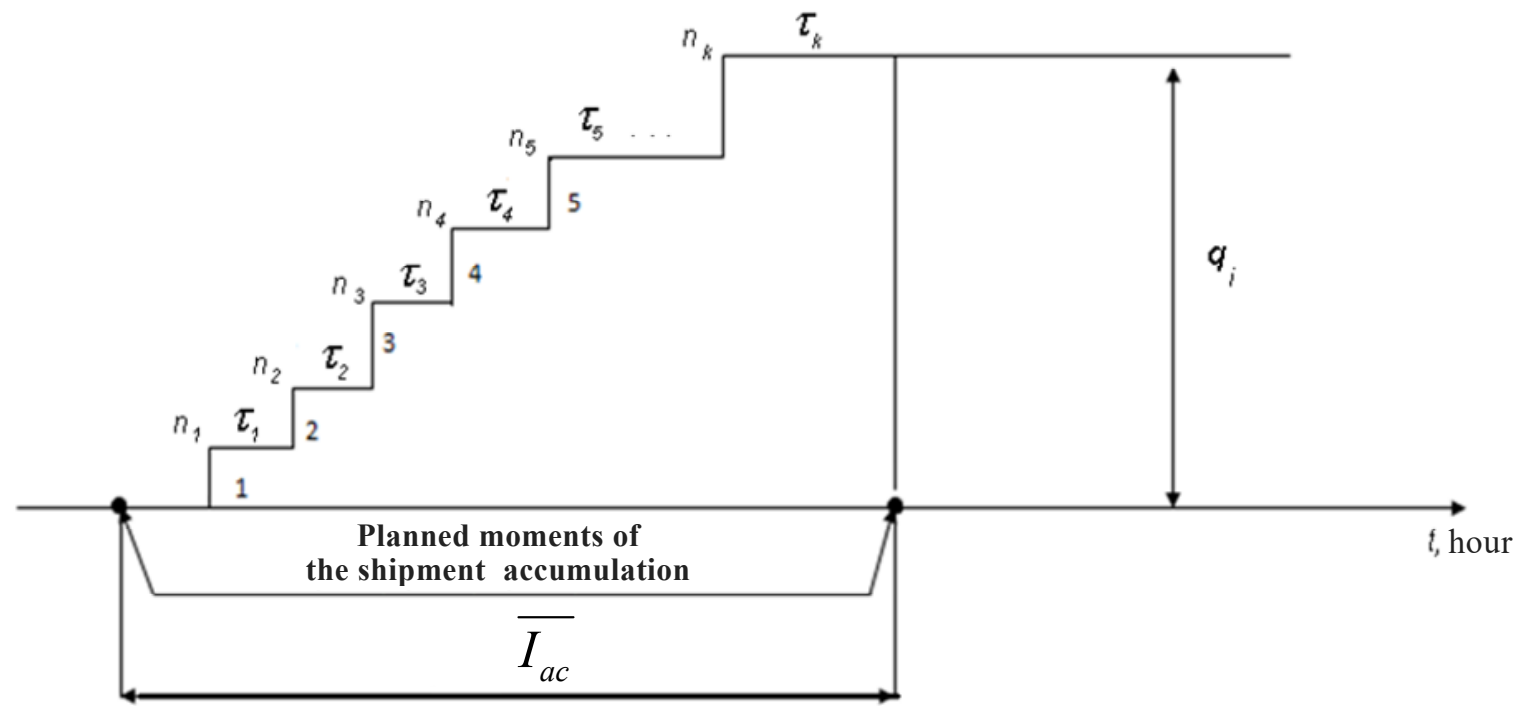

Fig. 2. The scheme of accumulating the shipment of products at the manufacturer's station 
The cost of unit-hour accumulation of one shipment of $i$ product type is determined by the formula:

$$
\begin{aligned}
& \mathrm{O}^{i}-g=n_{1}\left(\tau_{1}+\tau_{2}+\tau_{3}+\ldots+\tau_{i}\right)+ \\
& +n_{2}\left(\tau_{2}+\tau_{3}+\tau_{4}+\ldots+\tau_{i}\right)+\ldots+n_{i} \tau_{i}
\end{aligned},
$$

where $n, n_{2}, \ldots n_{i}$ - groups of products entering the warehouse of finished products and taking part in the accumulation $q_{i}$ of the shipment; $\tau_{1}, \tau_{2}, \tau_{3}, \ldots, \tau_{i}-$ intervals between groups of product units arrived at the manufacture's warehouse.

Since $n_{i}$ and $\tau_{i}$ are random variables (regardless sufficiently high regularity of the production process), therefore, $\mathrm{O}^{i}-g$ is a random variable. In this case, the mathematical expectation is determined by the formula:

$$
\begin{aligned}
& \mathrm{M}\left[\mathrm{O}^{i}-g\right]=\mathrm{M}\left[n_{1}\left(\tau_{1}+\tau_{2}+\ldots+\tau_{k}\right)\right]+ \\
& +\mathrm{M}\left[n_{2}\left(\tau_{2}+\tau_{3}+\ldots+\tau_{k}\right)\right]+M\left[n_{k} \tau_{k}\right]
\end{aligned}
$$

Using the property of average stability, the mathematical expectation of random variables with a sufficient degree of accuracy can be estimated from their average values. Having designated the number of intervals between groups of units of $i$ product during the interval $\overline{I_{a c}}$ as $k$, unit-hour of accumulating the shipment can be written as:

$$
\begin{aligned}
\mathrm{O}^{i}-g=\bar{n} \cdot \bar{\tau} \cdot k+\bar{n} \cdot \bar{\tau}(k-1)+\bar{n} \cdot \tau(k-2)+\ldots+\bar{n} \cdot \bar{\tau} \\
\mathrm{O}^{i}-g=\bar{n} \cdot \bar{\tau} \cdot[k+(k-1)+(k-2)+\ldots+1] \\
\mathrm{O}^{i}-g=\bar{n} \cdot \bar{\tau} \cdot \frac{(1+k) k}{2} \\
\bar{n} \cdot \bar{\tau} \cdot \frac{(1+k) k}{2}=\frac{1}{2} I_{a c} \cdot q_{i} \\
\bar{n} \cdot \bar{\tau} \cdot(1+k) k=I_{a c} \cdot q_{i} .
\end{aligned}
$$

From the last expression, the value of the shipment $q_{i}$ is determined by the amount of its accumulation interval $\overline{I_{a c}}$, which should be used to select the train schedule path for 24 hours for sending specific shipment of its total consumption per day $Q_{i}$ to specific consumer:

$$
\overline{I_{a c}}=\frac{\bar{n} \cdot \bar{\tau}(1+k) k}{q_{i}} .
$$

Equation (2) determines the value of the shipment $q_{i}$, inverse to the interval value $\overline{I_{a c}}$ :

$$
q_{i}=\frac{\bar{n} \cdot \bar{\tau}(1+k) k}{\overline{I_{a c}}} .
$$

Taking into account the known relationship between the amount of the batch $q_{i}$, daily volume of products shipped to specific consumer $Q_{i}$ and the length of the production cycle $T_{c}$ on the output of $i$ product by the enterprise $q_{i}=Q_{i} \cdot T_{c}$, we obtain the value of the production cycle:

$$
T_{c}=\frac{\bar{n} \cdot \bar{\tau}(1+k) k}{\overline{I_{\mathrm{H}}} \cdot \mathrm{O}^{i}-g} .
$$

Consequently, the linking of a stable schedule of dispatching finished products to the network with the production process of the enterprise is carried out through the process (duration) of the accumulating specific shipment. If, for convenience, intervals between the moments of the end of accumulating shipments indicate as $T_{a c}^{p r}$, the possible correlations between the value $T_{a c}^{p r}$ and arrival interval of empty cars under load $I_{a r}$ can be represented as follows: $I_{a r}=T_{a c}^{p r} \infty ; I_{a r}<T_{a c}^{p r}$; $I_{a r}>T_{a c}^{p r}$.

In addition, there is a similar ratios between duration of the shipment loading $t_{l}$ and shipment accumulation interval: $t_{l}=T_{a c}^{p r} ; t_{l}<T_{a c}^{p r} ; t_{l}>T_{a c}^{p r}$.

\subsection{Accumulating finished products at manufacturer's warehouse and the supply of empty cars with equal arrival intervals of empty cars and period of finished products accumulation}

Possible variants of different parameters ratios of the logistic interaction process of production with mainline rail transport are shown. On the basis of modelling possible variants of different parameters ratios of the logistic interaction process of production with mainline rail transport Table 1 was developed.

The proposed modelling is theoretical, based on a generalization of practical experience, in particular, JSC "Ukrainian Railway" and other railway operators.

The analysis of the results presented in Table 1 shows that different parameters ratios will give different results, which will vary depending on the duration of waiting for cargo operations by railway cars $t_{w t}^{c}$ and waiting for dispatching finished products from manufacturer's warehouse $t_{d e l}^{w}$, required car fleet $n_{\text {req }}^{c}$ and load of loading and unloading vehicles.

The most economical variant (variants №1 and №2 in Table 1) is necessary to accept as the basic condition for providing rational interaction of industrial and a mainline rail transport.

\section{Conclusions}

The transport factor occupies an important place in the development of all regions and the state as a whole, in international economy and foreign trade. Therefore, it is necessary to ensure the priority development of its components, taking into account the specific economic situation. Progress in the transport sector depends on the level of technical and technological development of all transport modes, which should be considered when using logistics economics for the development and implementation of logistic chain of cargo delivery (LCCD). 
Table 1. Results of modelling the interaction of the process of accumulating finished products at manufacturer's warehouse and the system of supplying empty cars in the logistics chain "Production - Mainline Rail Transport"

\begin{tabular}{|c|c|c|c|c|c|c|}
\hline № & $\begin{array}{l}\text { Ratios of arrival } \\
\text { intervals of empty } \\
\text { cars } I_{a r} \text { and period } \\
\text { of finished } \\
\text { products } \\
\text { accumulation } \\
T_{a c}^{p r}\end{array}$ & $\begin{array}{c}\text { Ratios of } \\
\text { loading time } t_{l} \\
\text { and period of } \\
\text { finished } \\
\text { products } \\
\text { accumulation } \\
T_{a c}^{p r}\end{array}$ & $\begin{array}{c}\text { Car } \\
\text { downtimes } \\
\text { in waiting } \\
\text { for cargo } \\
\text { operations } \\
t_{w t}^{c}\end{array}$ & $\begin{array}{c}\text { Delays of } \\
\text { finished } \\
\text { products at the } \\
\text { manufacturer's } \\
\text { warehouse } \\
t_{d e l}^{w}\end{array}$ & $\begin{array}{l}\text { Level of the } \\
\text { required car } \\
\text { fleet to } \\
\text { carry out } \\
\text { transportation } \\
n_{\text {req }}^{c}\end{array}$ & $\begin{array}{c}\text { Consequences of the lack of } \\
\text { harmonization in the } \\
\text { accumulating finished products } \\
\text { at the manufacturer's } \\
\text { warehouse and supplying } \\
\text { empty cars }\end{array}$ \\
\hline 1. & $I_{a r}=T_{a c}^{p r}$ & $t_{l}=T_{a c}^{p r}$ & $t_{w t}^{c}=0$ & $t_{d e l}^{w}=0$ & $n_{\text {req }}^{c}=$ optim & $\begin{array}{l}\text { Dispatch of finished products } \\
\text { is rhythmic }\end{array}$ \\
\hline 2. & $I_{a r}=T_{a c}^{p r}$ & $t_{l}<T_{a c}^{p r}$ & $t_{w t}^{c}=0$ & $t_{d e l}^{w}=0$ & $n_{\text {req }}^{c}=$ optim & $\begin{array}{l}\text { Dispatch of finished products } \\
\text { is rhythmic, breaks in the } \\
\text { operation of loading and } \\
\text { unloading vehicles }\end{array}$ \\
\hline 3. & $I_{a r}=T_{a c}^{p r}$ & $t_{l}>T_{a c}^{p r}$ & $t_{w t}^{c}>0$ & $t_{d e l}^{w}>0$ & $n_{r e q}^{c}=$ optim & $\begin{array}{l}\text { Dispatch of finished products } \\
\text { is rhythmic, car downtimes } \\
\text { and delays of finished products } \\
\text { at manufacturer's warehouse }\end{array}$ \\
\hline 4. & $I_{a r}<T_{a c}^{p r}$ & $t_{l}=T_{a c}^{p r}$ & $t_{w t}^{c} \gg>0$ & $t_{d e l}^{w}=0$ & $n_{\text {req }}^{c}>$ optim & $\begin{array}{l}\text { Dispatch of finished products } \\
\text { is rhythmic, car downtimes }\end{array}$ \\
\hline 5. & $I_{a r}<T_{a c}^{p r}$ & $t_{l}<T_{a c}^{p r}$ & $t_{w t}^{c} \gg>0$ & $t_{d e l}^{w}=0$ & $n_{\text {req }}^{c}>$ optim & $\begin{array}{l}\text { Dispatch of finished products } \\
\text { is rhythmic, breaks in the } \\
\text { operation of loading and } \\
\text { unloading vehicles }\end{array}$ \\
\hline 6. & $I_{a r}<T_{a c}^{p r}$ & $t_{l}>T_{a c}^{p r}$ & $t_{w t}^{c} \gg>0$ & $t_{d e l}^{w} \gg>0$ & $n_{\text {req }}^{c}>$ optim & $\begin{array}{l}\text { Dispatch of finished products } \\
\text { is non-rhythmic, car } \\
\text { downtimes and delays of } \\
\text { finished products at } \\
\text { consignor's warehouse }\end{array}$ \\
\hline 7. & $I_{a r}>T_{a c}^{p r}$ & $t_{l}=T_{a c}^{p r}$ & $t_{w t}^{c}=0$ & $t_{d e l}^{w} \gg>0$ & $n_{\text {req }}^{c}<$ optim & $\begin{array}{l}\text { Dispatch of finished products } \\
\text { is non-rhythmic, delays of } \\
\text { finished products at } \\
\text { consignor's warehouse, breaks } \\
\text { in the operation of loading and } \\
\text { unloading vehicles }\end{array}$ \\
\hline 8. & $I_{a r}>T_{a c}^{p r}$ & $t_{l}<T_{a c}^{p r}$ & $t_{w t}^{c}=0$ & $t_{d e l}^{w} \gg>0$ & $n_{\text {req }}^{c}<$ optim & $\begin{array}{l}\text { Dispatch of finished products } \\
\text { is non-rhythmic, breaks in the } \\
\text { operation of loading and } \\
\text { unloading vehicles }\end{array}$ \\
\hline 9. & $I_{a r}>T_{a c}^{p r}$ & $t_{l}>T_{a c}^{p r}$ & $t_{w t}^{c}=0$ & $t_{d e l}^{w} \gg>0$ & $n_{\text {req }}^{c}<$ optim & $\begin{array}{l}\text { Dispatch of finished products } \\
\text { is non-rhythmic, delays of } \\
\text { finished products at } \\
\text { consignor's warehouse }\end{array}$ \\
\hline
\end{tabular}

The efficient functioning of the logistics chain "Production - Transport - Consumption" can be provided under market conditions when building relationships between all its structures using the model of transport process compromise management. The principles of equal partnership in the transport services market between the railways and cargo owners, taking into account the specifics of their technological processes and diverse economic interests should be putted as the basis of such a model. To achieve this, a fair competitive environment in which all transport modes and private business should have equal rights and opportunities for operating and own development depending on the real position in the transport market should be formed. Moreover, it is important to provide market laws in the transport sector with the introduction of a fair tariff system, eliminating the current practice of subsidizing private companies in the sector at the expense of rail transport. Only in such a way it is possible to ensure the financial stability of railways, which will facilitate their rapid technical and technological upgrading and a significant increase in the transport services' quality of cargo owners.

\section{References}

1. D.R. Martinelli, H.Teng, Transportation Research Part C: Emerging Technologies, 4, 1: 33-49 (1996) 
2. G. de O. Ramos, A.L.C. Bazzan, Proceedings of the 15th Annual Conference on Genetic and Evolutionary Computation: 473-480 (2015)

3. H. Bar-Gera, Origin-based algorithms for transportation network modeling (National Institute of Statistical Sciences, 1999)

4. N. Haque, M.A. Hossain, T. Islam, J. Khalil, A trip assignment software for auto trips. Dhaka: Ahsanullah University of Science and Technology (2014)

5. A.L.C. Bazzan, Proceedings of the 14th Annual Conference on Genetic and Evolutionary Computation: 43-50 (2012)

6. A.L.C. Bazzan, D. Cagara, B. Scheuermann, Proceedings of IEEE Symposium on Computational
Intelligence in Vehicles and Transportation Systems: 43-50 (2014)

7. L. Kuttner, Tagungsband Multikonferenz Wirtschaftsinformatik:1923-1934 (2018)

8. J.A. Sabino, J.E. Leal, T. Stützle, M. Birattari, Pesquisa Operacional, 30, 2: 487-514 (2010)

9. B. Abramovic, E. Nedeliakova, M. Panak, D. Sipus, Business Logistics in Modern Management:17: 1528 (2017)

10. D.V. Lomot'ko, Formation transport process of railways Ukraine on the basis of logistical principles. Kharkiv: Ukrainian State Academy of Railway Transport (2008)

11. P.O. Yanovsky, Railway transport of Ukraine, 1: 41-49 (2014) 